\title{
Neuro-immune modulation of the thymus microenvironment (Review)
}

\author{
FIORENZO MIGNINI $^{1}$, MAURIZIO SABBATINI ${ }^{2}$, LAURA MATTIOLI ${ }^{1}$, \\ MONICA COSENZA ${ }^{1}$, MARCO ARTICO ${ }^{4}$ and CARLO CAVALLOTTI ${ }^{3}$ \\ ${ }^{1}$ Human Anatomy, School of Drug and Health Products Science, University of Camerino, I-62032 Camerino; \\ ${ }^{2}$ Human Anatomy, Department of Health Sciences, University of Eastern Piedmont ‘Amedeo Avogadro', I-28100 Novara; \\ Departments of ${ }^{3}$ Sensory Organs and ${ }^{4}$ Anatomical, Histological, Medico-legal and Locomotor System Sciences, \\ Sapienza University of Rome, I-00185 Rome, Italy
}

Received December 3, 2013; Accepted February 13, 2014

DOI: $10.3892 /$ ijmm.2014.1709

\begin{abstract}
The thymus is the primary site for T-cell lymphopoiesis. Its function includes the maturation and selection of antigen specific $\mathrm{T}$ cells and selective release of these cells to the periphery. These highly complex processes require precise parenchymal organization and compartmentation where a plethora of signalling pathways occur, performing strict control on the maturation and selection processes of $\mathrm{T}$ lymphocytes. In this review, the main morphological characteristics of the thymus microenvironment, with particular emphasis on nerve fibers and neuropeptides were assessed, as both are responsible for neuro-immune-modulation functions. Among several neurotransmitters that affect thymus function, we highlight the dopaminergic system as only recently has its importance on thymus function and lymphocyte physiology come to light.
\end{abstract}

\section{Contents}

1. Introduction

2. Genesis of the thymus microenvironment

3. Endocrine function of thymus microenvironment

4. Anatomy of thymus innervation

5. Regulatory peptides

6. Conclusions

Correspondence to: Dr Maurizio Sabbatini, Department of Health Sciences, University of Eastern Piedmont 'Amedeo Avogadro', Via Solaroli 17, I-28100 Novara, Italy

E-mail: maurizio.sabbatini@med.unipmn.it

Key words: thymus parasympathetic nerve, thymus sympathetic nerve, thymus innervation, thymus peptidergic nerve, thymus dopaminergic system

\section{Introduction}

The thymus is the primary site for T-cell lymphopoiesis, providing a coordinated environment for critical factors to induce and support lineage commitment, differentiation and survival of thymus-seeding cells. The function of the thymus includes the maturation and selection of antigen-specific T cells and selective release of these cells to the periphery. The maturation process consists of the development of T-cell antigen receptors with high diversity that are capable of binding to different antigens, while the selection process consists of eliminating those cells that support receptors that can bind to antigens of the organism itself.

T-cell differentiation is a highly complex process that includes progressive acquisition of different membrane markers and rearrangement of the genes coding for the antigen-specific T-cell receptor (TCR). This diversity of markers is generated by re-arrangement of the TCR genes from a set of germ-line genes (1-3). It has been found that the selection of the T-cell repertoire and rearrangement of TCR genes are not purely automatic genetically programmed mechanisms; instead, they are stepwise processes, controlled and probably induced by a variety of stromal cells in different regions of the organ. This insight has led to the concept of the thymus microenvironment, a three-dimensional network composed of several distinct cell types, such as epithelial cells, macrophages, dendritic cells and fibroblasts, as well as extracellular matrix (ECM) elements $(4,5)$. Evidence from molecular biology and immunohistochemical findings have revealed that there are several different microenvironments in the thymus, each responsible for a specific step of the stepwise process of T-cell development and differentiation (6-8). Within the microenvironment, different types of intercellular communications occur and probably play a role in T-cell differentiation $(9,10)$. Furthermore, an increasing amount of experimental data have indicated the presence of an intrinsic thymus innervation that actively participates to modulate the development and maturation of $\mathrm{T}$ cells in the thymus microenvironment $(11,12)$.

\section{Genesis of the thymus microenvironment}

The thymus parenchyma is characterized by a succession of different microenvironments that offer specific assistance 
to several T-cell maturation steps. This complex cellular architecture of the thymus parenchyma has its origin in the heterogeneous embryonal genesis of the organ. The long-held understanding that the thymus develops in the embryo from the endoderm of the third pharyngeal pouch, and from the ectoderm of the branchial clefts and related mesenchyma, which derive from pharyngeal arch $(13,14)$, has been challenged. In their study, Gordon et al (15) showed through labelling experiments that ectoderm may not be involved in thymus genesis, and that endoderm cells alone seem to be sufficient to generate a complete thymic microenvironment. Recently, several studies have provided more support for the 'endodermic-centric' model of thymus organogenesis (16).

In the human foetus at about the 9th week of embryonal life, the thymus primordium begins to be invaded by lymphoid stem cells, and following this invasion the epithelial stroma becomes reticulated. During the 9th to 12 th week of embryonal life, the surface of the thymus primordium becomes indented by mesenchymal septae, which begin to separate thymus parenchyma into pseudolobuli. In the 17 th week of embryonal life, these septae reach the cortico-medullary junction. At the 12th week of embryonal life, the differentiation of cortex and medulla becomes evident, and is completed at approximately the end of the 4th fetal month. From that point on, the thymus delivers thymocytes to the peripheral lymphoid organs and is to be considered fully functional. In the postnatal thymus, extended perivascular spaces with argyrophilic fibers, containing capillaries, arterial venous blood vessels and lymphatic vessels, sprouting from these septae, are predominantly found between the cortex and medulla (17).

The thymus continues to grow between birth and puberty and then begins its atrophic phase, when the organ is primarily replaced with fat (a phenomenon known as 'organ involution'). The atrophy is accompanied by increased circulating levels of sex hormones. Notably, it has been observed that chemical or physical castration of an adult subject results in the thymus increasing in size and activity (18). During this organ involution, the thymus becomes progressively smaller, and its microanatomy changes significantly with a loss of thymic epithelial cells (TEC) and a decrease of lymphopoiesis $(17,19)$. However, remnants of thymic epithelial tissue with a cortical lymphocyte population are preserved, and for the entire life of the subject the thymus acts as a site of T-cell differentiation and maturation, with only partial reduction of endocrine physiology (17).

The macroscopic structure of the mature thymus organ is divided into lobules that have an outer part known as the cortex and an inner core known as the medulla, separated by the cortico-medullary border. T-cell maturation and development occur along a cortico-medullary cell gradient, in which immature T-cells acquire step by step a particular expression of the membrane factor, following exposure to different signals regulated by a complex interaction with the thymic microenvironment. Furthermore the T-cell maturation steps, along cortical thickness, have evidenced a different expression of pro-thymocyte membrane proteins that lead to subdivision of the cortex into the outer and deep cortex $(20,21)$. An important site inside the thymus parenchyma is the perivascular site, through which immature $\mathrm{T}$ cells enter the thymus (cortical perivascular site) or exit the thymus when mature (medullar perivascular sites). In particular, the perivascular spaces at the cortico-medullary junction are narrowly interdigitated with the thymic epithelial tissue and are the site of exchange between the thymic epithelial region and the periphery. Both lymphatic stem cells as well as precursors of macrophages, presumably monocytes, invade the thymus and settle in the presumptive cortex and medulla of the fetal thymus (22-24).

The different regions into which the thymus parenchyma is divided show unusual cytological characteristics with complex humoral and paracrine relationships between stromal cells and developing pro-thymocytes.

The thymic epithelium is the major component of the thymic microenvironment and plays important and multifaceted roles in early events of T-cell differentiation $(25,26)$ in at least two distinct ways: i) through secretion of a variety of polypeptides and thymic hormones and ii) through cell-to-cell contacts, including those occurring through classical adhesion molecules $(10,25,27)$. However, the submorphological aspects are not only different in the TEC types, but there are also distinctions in the antigenic pattern $(10,25)$. Van de Wijngaert et al (28), studying sections obtained from healthy donors, classified epithelial cells into six types, according to their ultrastructural appearance and location in the human thymus. More recently, transmission electron microscope observations have confirmed that there are four functional subtypes of medullar reticulo-epithelial (RE) cells; according to their morphological appearance, these subtypes are termed undifferentiated, squamous, villous and cystic (26).

The structure of the ECM is also important in defining the properties of thymus microenvironments as it affects the reciprocal relationships between cells and tissue organization (29-31). The ECM of the thymus is a well-organized macromolecular system containing collagen (types I and IV) and other glycoproteins (fibronectin, laminin), with a variable composition in different compartments of the organ (32). Of note, although chemokines and ECM proteins can drive thymocyte migration, a combined role of these molecules likely concurs for the resulting migration patterns of thymocytes in their various differentiation stages. Among ECM moieties, there are proteins with opposing functions, such as laminin or fibronectin vs. galectin-3, which promote, respectively, adhesion and de-adhesion of thymocytes to the thymic microenvironment (33). Thus, the physiological migration of thymocytes should be conceived as a resulting vector of multiple, simultaneous or sequential stimuli, involving chemokines, adhesive and de-adhesive ECM proteins (31). Moreover, these interactions may be physiologically regulated in situ by matrix metalloproteinases (MMPs) $(34,35)$ and hormonally regulated $(9,36)$.

\section{Endocrine function of the thymus microenvironment}

Thymus physiology is pleiotropically influenced by hormones, but it also expresses endocrine functions, secreting several humoral factors, such as thymopoietin and the thymosins, which are involved in the maturation of prothymocytes and assist mature thymocytes in their peripheral tissue colonizing $(9,37)$.

The thymic hormones are produced by the RE cellular network of the thymic stromal cellular microenvironment. The thymic hormones have different influences on T-cell maturation: thymopoietin induces the phenotypic differentiation of 
$\mathrm{T}$ precursors; $\beta-3$ and $\beta-4$ thymosins induce maturation of prothymocytes; $\alpha-7$ thymosin is involved in the generation of suppressor T lymphocytes; and $\alpha-1$ thymosin influences the early and late stages of $\mathrm{T}$ maturation $(37,38)$. The intrathymic compartmentalization of secretory cells is also noteworthy, in that it corresponds to various stages of T-lymphocyte differentiation (39).

Thymic RE cells also produce numerous cytokines, including IL-1, -3, -6, -7 and G-CSF, M-CSF, which likely are important during the various stages of thymocyte activation and differentiation $(26,29,40)$.

In the RE cells of the thymus we have a unique phenomenon of molecular biology, because there is the presence of pituitary hormones, such as growth hormone, prolactin, adrenocorticotopic hormone and thyroid-stimulating hormone, as well as secretion of neuropeptides, production of a number of interleukins and growth factors, and expression of the receptors for all these substances $(9,41)$.

\section{Anatomy of thymus innervation}

The anatomical innervation of the thymus is complex, due to the numerous nerve pathways that supply it. The human thymus is innervated by nerve fibers originating from postganglionic cell bodies located in the superior cervical and stellate ganglion (formed by the fusion of the third cervical ganglion with the first thoracic ganglion) of the sympathetic chain (42). These nerve fibers reach the thymus through the perivascular plexus, leading the sympathetic component of visceral innervation. In addition, the thymus is reached by fibers running into the vagal branches of the superior and inferior (or recurrent) laryngeal nerve. There is debate regarding whether these fibers are parasympathetic $(12,43-46)$ or not $(47,48)$. All these nerve fibers form a rich perivascular plexus that branches along parenchymal vessels, thus becoming the access way for nerve fibers. In this case, the sympathetic and parasympathetic component may be mixed and cause some enigmatic responses (49). Sympathetic and parasympathetic nerve fibers enter the thymus along with blood vessels and branch into the cortex, the capsular and septal system, the cortico-medullary junction and the medulla $(11,50)$ (Fig. 1A).

The sympathetic noradrenergic innervation. The sympathetic noradrenergic innervation of the thymus has been identified as tyrosine hydroxylase (TH) immunohistochemical-positive nerve fibers (51). In the subcapsular area around vasculature, noradrenergic nerve profiles are predominantly limited to the cortex with a slightly higher density near the cortico-medullary junction. At this level, noradrenergic fibers of septal origin run in venous sinuses, and from that point they reach the thymic cortex and medulla $(50,52)$.

Several direct interactions have been described between noradrenergic nerve fibers and thymus parenchymal cells such as mast cells $(53,54)$, cortico-medullary macrophages (53), and TEC of deep cortex and medulla (55). Even if conventional electron microscopy was unable to identify specific contacts between these cells and sympathetic neuroeffector junctions, it has been supposed that a diffusible release of neurotransmitters may influence the physiology of these cells (56). The strict association of noradrenergic fibers with thymus stromal cells and TEC strongly supports the hypothesis that the secretory activity of epithelial cells is subject to neuroimmuomodulation (57). Previous studies have demonstrated that in the thymus, the release of noradrenaline from sympathetic nerve terminals is of axonal and vesicular origin $(51,58)$.

Noradrenaline released from nerve terminals seems to have a direct role in the maturation of thymocytes, mediated through the activation of $\beta$-adrenoceptors; it has been observed that noradrenaline inhibits the proliferation of thymocytes and promotes their differentiation in vitro $(39,57,59)$. Noradrenergic nerve fibers run in close contact with TEC, and TEC expresses $\beta$-adrenoceptors $(55,56)$. The same type of TECs form the blood-thymus barrier in the outer thymic cortex, and may be targeted by noradrenaline released from perivascular nerves to regulate the entry trafficking of proto-thymocytes. Furthermore, some types of TECs are also the main cells responsible for performing thymus microenvironment, in which the relationships between TEC and noradrenergic fibers may directly affect the maturation and differentiation of thymocytes to T-lymphocytes $(57,60,61)$.

Other sympathetic catecholamines have been found in thymus parenchyma as well $(11,54,58,62)$. In particular, it has been observed that catecholamines influence the synthesis of cytokines, which are known to affect the T-cell proliferative/differentiative program (63).

It should be noted that direct production of noradrenaline $(64)$, dopamine $(65,66)$ and other catecholamines has been found in thymocytes and stromal cells, which act in an autocrine/paracrine manner to regulate several immune functions such as differentiation, apoptosis and cytokine production $(39,63)$.

The parasympathetic innervation. The parasympathetic innervation of the thymus has been demonstrated by acetylcholinesterase (AChE) or choline acetyltransferase (ChAT) histochemistry (44). The two methods have yielded some variable results, and therefore there is still doubt as to whether there is parasympathetic innervation of the thymus $(47,48)$. However, several authors have delineated the presence of parasympathetic fibers, consisting primarily of non-myelinated C-fibers $(12,43,67,68)$. They pass from the capsular region to the cortex and reach the medulla running in association with blood vessels $(12,68,69)$. In vivo studies of the effects of efferent vagal innervations of rat thymus have shown that nicotinic receptors mediate mechanisms responsible for lymphocyte release from the thymus (70).

The neurotransmitter acetylcholine is involved in the mutual interplay between developing $T$ cells and thymic epithelium, and thereby may influence the generation of T-cell repertoires $(71,72)$. Moreover, cholinergic agonists may influence T-cell maturation, negatively affecting thymocyte apoptosis (nicotinic effect) (73). Thymic acetylcholine is mainly derived from thymocytes themselves, and its production and release depend on the activation of thymic lymphocytes $(71,72)$. The occurrence of acetylcholine secretion by cells of thymus parenchyma renders cholinergic innervation unclear.

Thus, sympathetic noradrenergic and parasympathetic cholinergic nerve fibers innervate the vasculature and parenchymal fields of the thymus: the noradrenergic innervation is prominent in the subcapsular area, the deep cortex and the 
connective tissue of the organ (capsule, interlobular septae) while cholinergic nerve endings are observed in the cortex and abundantly at the corticomedullary junction.

Another minor component of the thymus nerve supply is the phrenic nerve, a somatic nerve originating in the cervical plexus (74). The phrenic nerve accesses the intraparenchymal subcapsular region directly through the connectival capsula of thymus lobules, forming a rich subcapsular intraparenchymal plexus without being involved in the perivascular plexus. Phrenic nerve branching has not been found in other regions of thymic parenchyma outside the subcapsular region (12).

The strict association between nerve fibers and blood vessels strongly supports the hypothesis that autonomous innervation is also involved in controlling T-cell trafficking, i.e., both entry of $\mathrm{T}$ cells into the thymus and their exit from the thymus as mature $\mathrm{T}$ cells.

The dopaminergic system in the thymus. Although modulation of immune responses by the noradrenergic system and its main neurotransmitter, noradrenaline, as well as adrenaline, has been extensively investigated (75), little information is available concerning modulation by the other catecholamines such as dopamine. It was previously shown that the dopaminergic system is essential in the intrathymic microenvironment for modulating and coordinating the homeostasis of thymocyte survival or death by apoptosis (76,77).

Experimental findings have indicated that the thymus expresses a dopaminergic system characterized by the presence of dopamine, vesicular monoamine transporters and the five subtypes of dopamine receptors $(66,78)$. In particular, in the rat thymus, the dopamine system was found to be expressed in the cortico-medullary junction and in the medulla, but not in the thymic cortex (12). However, DAT immune reaction was also found in the wall of arteries located in the septa of connective tissue as well as in the medulla, with a reticular localization and an apparent negative reaction of thymocytes (78). Other authors have identified dopamine synthesis and storage in dendritic cells, indicating a functional role of dopamine in cell-cell communication in the thymic microenvironment as well (65).

Following specific denervation (12), the persistence of D1 and D2 receptor expression in the thymus medulla was shown, while dopamine and DAT disappeared with the loss of sympathetic innervation, indicating their specific location on nerve fibers. These findings suggest that dopamine originates from thymus parenchymal cells and from sympathetic neuroeffector plexuses, and is released in the lymphoid microenvironment, emphasizing the importance of a paracrine/secretory loop of dopamine within the thymus microenvironment $(65,79)$.

Dopamine receptors have been identified in peripheral mature lymphocytes (80). High doses of dopamine in vitro may inhibit mitogen-induced proliferation and promote apoptosis in lymphocytes (81-83). Data from in vivo studies have provided conflicting results, with evidence for both stimulatory and inhibitory effects of dopamine on lymphocyte function (84-86). However, previous studies have offered a detailed focus on the action of dopamine in lymphocytes. In human $\mathrm{T}$ cells, during TCR activation, D4 receptor was observed to be associated with lymphocyte quiescence by upregulating the transcription factor KLF2 (87). Following cytofluorimetric analysis, Mignini et al (77), found a modulated expression of dopaminergic markers on maturing thymocytes. In particular, during the lineage selection of thymocytes, the acquisition of the $\mathrm{CD}^{+}$or $\mathrm{CD}^{+}$identity of thymocytes is accompanied by particular modulation of dopaminergic system expression on the two cells $(65,77,79)$.

Taken together, these findings indicate that the dopaminergic system is widely involved during the last steps of lymphocyte maturation in the thymus parenchyma.

\section{Regulatory peptides}

Regulatory peptides have been shown to be involved in the regulation of immune processes in several animal and human studies, and a role for neuropeptides in T-cell development has been investigated (9,88-90). In the human thymus, neuropeptides such as neuropeptide Y (NPY), vasoactive intestinal polypeptide (VIP), substance $\mathrm{P}$ (SP), calcitonin gene-related peptide (CGRP), and neurotensin (NT) have been described. These neuropeptides have been observed to be present in cells and nerve fibers, indicating a complex scenario in which neuropeptides seem to function as a secretory system and a modulator system of neurotransmission (11,90) (Fig. 1B).

$N P Y$. Neuropeptide $\mathrm{Y}$-containing $\left(\mathrm{NPY}^{+}\right)$nerve fibers have a distribution similar to that of $\mathrm{TH}$-immunoreactive nerve fibers $(53,69,91,92)$. Chemical denervation of noradrenergic nerve fibers with 6-hydroxydopamine (6-OHDA) depletes NPY in the rat thymus, suggesting that NPY is co-localized with noradrenaline in sympathetic nerves $(4,58)$. Nerve fibers containing NPY extend from the subcapsular and septal plexuses into superficial and deep cortical regions, the CM-J, and medulla, mainly detected in relation to the vasculature, while only a few NPY ${ }^{+}$fibers were observed in the parenchyma of the same zone. The densest innervation occurs at the corticomedullary junction (90).

$\mathrm{NPY}^{+}$fibers were observed to arborize between thymocytes and associated cells such as mast cells or macrophages (93). This intimate contact suggests a role for NPY in the development of thymocyte modulation $(94,95)$. In particular, the preferential localization of NPY fibers in perivascular spaces suggests that the effects of NPY in human thymus may be marked by compartment specificity, and may indicate a focalised role for NPY in thymocyte migration (90).

VIP. Several findings support the hypothesis that VIP may modulate thymocyte development. It is known that VIP distribution is linked to key zones in the thymus lobule, and thus it is the primary signalling factor in modulating thymic responses to different stimuli (96). The distribution of VIP-positive fibers is similar to that of TH- and NPY-containing nerve fibers, although they are expressed with lower density $(90,97)$. In all the thymus compartments, VIP immunoreactivity was observed with a varicose profile in perivascular sites and with a profile of very fine free fibers in parenchymal sites. A wide reticular pattern of $\mathrm{VIP}^{+}$fiber staining was observed in the subcapsular zone, branching along the perivascular sites, and not in the parenchyma. In the septal zone, some $\mathrm{VIP}^{+}$fibers left vessels to enter the deep cortex. In the deep cortex, the CM-J zone, and in the medulla, VIP ${ }^{+}$fibers were present adjacent to blood vessels 
A

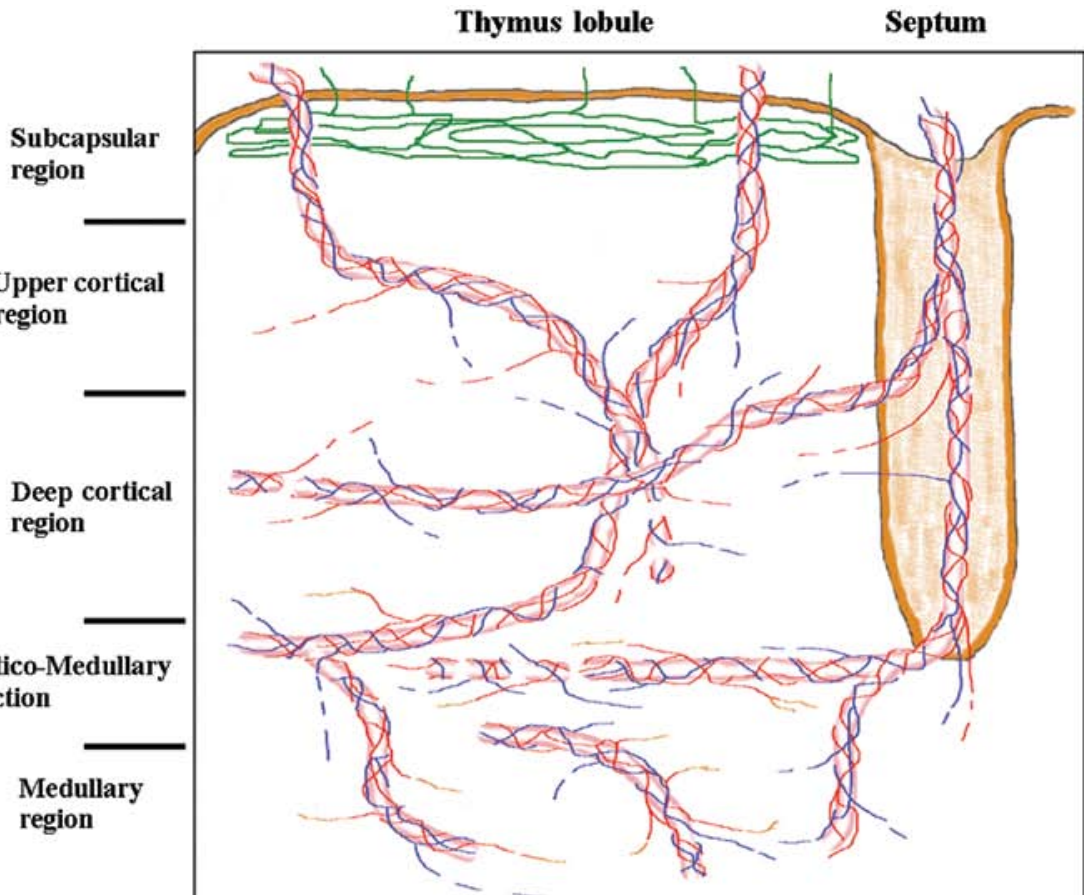

B

Subcapsular
region

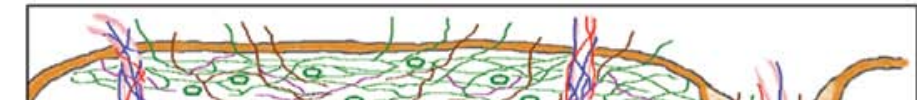

Upper cortical region

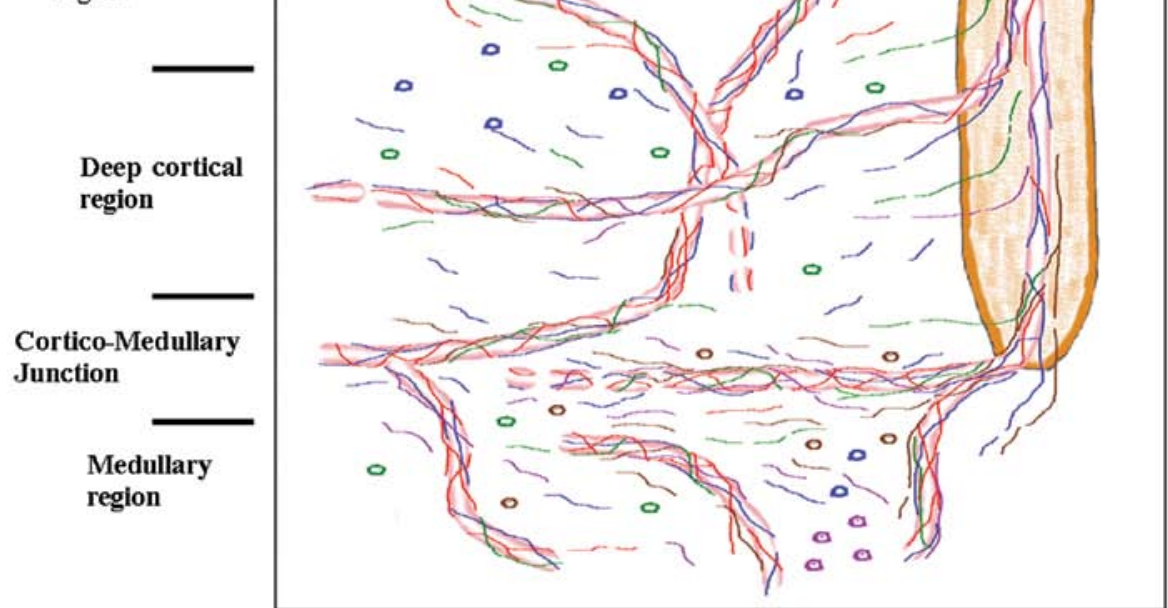

Figure 1. (A) Graphic drawing of intrinsic innervation pattern of the thymus lobule. Green line, phrenic nerve fibers; red line, sympathetic nerve fibers; blue line, parasympathetic nerve fibers; orange line, dopaminergic-sympathetic nerve fibers. (B) Graphic drawing of neuropeptides pattern of the thymus lobule. Green line, $\mathrm{SP}^{+}$nerve fibers; red line, neuropeptide Y-containing $\left(\mathrm{NPY}^{+}\right)$nerve fibers; blue line, $\mathrm{VIP}^{+}$nerve fibers; violet line, neurotensin-immunopositive $\left(\mathrm{NT}^{+}\right)$ nerve fibers; brown line, $\mathrm{CGRP}^{+}$nerve fibers; green cells, $\mathrm{SP}^{+}$; blue cells, $\mathrm{VIP}^{+}$; violet cells, $\mathrm{NT}^{+}$; brown cells, $\mathrm{CGRP}^{+}$.

and free fibers in intraparenchymal sites. In thymus cortex and medulla, VIP immunoreactivity was also observed in cells, often in proximity to $\mathrm{VIP}^{+}$fibers, whereas no $\mathrm{VIP}^{+}$cell localization was observed in the subcortical, septal or CM-J zones (90). The presence of $\mathrm{VIP}^{+}$fibers and cells in the cortex lobular zone may be the neuroanatomical basis for the modulatory effect of VIP observed on the proliferation/apoptosis balance on $\mathrm{CD} 4{ }^{+} \mathrm{CD}^{+}$double-positive thymocytes $(88,98)$. Similarly, the presence of $\mathrm{VIP}^{+}$fibers and cells in CM-J and medulla may be the neuroanatomical basis for the VIP downregulation of lymphocyte mobility from the thymus.
Functional findings have shown that VIP primarily affects three important aspects of thymocyte function: cytokine production, mobility and apoptosis. Through apoptosis, VIP affects T-cell development, participating in the generation and maturation of immune cells and in thymic response to stressful conditions. Immunomodulatory activity of VIP is mediated, at least in part, by the production of cytokines which are known to control intrathymic T-cell development (99).

In the human thymus, NPY and VIP are the main peptidergic components in terms of diffusion, localized in cholinergic and adrenergic fibers, respectively (90). 
$S P . \mathrm{SP}^{+}$fibers were found to be associated with the vasculature and others were found freely branching in the parenchyma. In the subcapsular zone, $\mathrm{SP}^{+}$fibers were observed as parenchymal fibers only, and were not associated with perivascular spaces. Instead, they were detected as the only neuropeptidepositive fibers occurring in the subcapsular zone parenchyma. In deeper cortical zones, rare $\mathrm{SP}^{+}$fibers were associated with perivascular sites. However, free $\mathrm{SP}^{+}$fibers were distributed in parenchyma, mainly as branching of septal $\mathrm{SP}^{+}$fibers. At the corticomedullary junction, $\mathrm{SP}^{+}$fibers were found branching in association with the vasculature, with few $\mathrm{SP}^{+}$fibers running towards the medullary zone which received only a sparse parenchymal innervation of $\mathrm{SP}^{+}$fibers $(53,90,91)$. A close association was observed between free SP-immunoreactive fibers and macrophages at the corticomedullary junction, and between these nerve fibers and macrophages and mast cells along the capsule, interlobular septum and cortex $(53,100,101)$. $\mathrm{SP}^{+}$cells exhibited a cell layer in subcapsular localization, and scattered cells were observed in the cortex and medulla. A close association was observed between free SP-immunoreactive fibers and SP-positive cells $(90,101)$.

The parenchymal, but not perivascular, distribution of $\mathrm{SP}^{+}$cells in the subcapsular zone, and the occurrence of the well-defined subcortical localization of $\mathrm{SP}^{+}$cells, suggest an important role for this neuropeptide in the proliferation and first step of maturation of double-negative (CD4-CD8-) thymocytes (102). Mignini et al (90) have noted a similar distributive pattern of phrenic nerve fibers and $\mathrm{SP}^{+}$fibers in the subcapsular zone of human thymus, an observation that suggests the potential co-localization of the two systems.

CGRP. CGRP-immunoreactive nerve fibers with vascular and parenchymal localization $(53,91,93)$ were detected. Similar to $\mathrm{SP}^{+}$fibers, these nerve fibers travel along the capsule and interlobular septa and enter the thymic cortex from the septum. At the cortical level, these peptidergic fibers branch around immature thymocytes in cortical parenchyma or enter the medulla $(92,100,101)$. SP-/CGRP-immunoreactive nerve fibers were also found adjacent to mast cells in the capsule, interlobular septum, and at the corticomedullary junction $(53,100,103)$.

Sparse cells positive for CGRP were noted during the late embryonic period at the cortico-medullary boundary and in the medulla. The number of these cells increases in adulthood and is reduced in the thymus of aged mice (104). Thymic lymphocytes synthesize CGRP, which probably acts as a paracrine mediator in immune cells; intimate contact with macrophages and mast cells was observed (105).

Functional and pharmacological analyses have shown that CGRP mediates different immune responses of thymocytes via distinct receptor subtypes $(106,107)$.

CGRP affects the proliferation of CD4-positive T cells, suggesting that the neuropeptide is an inhibitor of the proliferation of virgin mature $\mathrm{T}$ cells while they remain in the thymus (106). Cytometric analysis revealed that in cultures the majority of thymocytes undergoing CGRP-induced apoptosis belong to the CD4/CD8- positive (double-positive/DP) cell types $(107,108)$. Endogenous CGRP may serve as a natural inhibitor of inappropriate induction of mature, antigen-sensitive cells in the thymus, as well as play a role in investigations on thymocyte.
CGRP and SP are likely fundamental physiological regulatory substances that are crucial in the differentiation, maturation and proliferation of thymocytes and are likely to be involved in the promotion of apoptosis in the thymus $(102,107,108)$.

$N T$. Unlike observations in experimental animals $(53,109)$ the occurrence of NT-immunopositive $\left(\mathrm{NT}^{+}\right)$fibers was detected in several zones of human thymus lobule, as free fine fibers. $\mathrm{NT}^{+}$fibers was detected in the CM-J and medullary zones. Furthermore, $\mathrm{NT}^{+}$cells were detected in the medullary zone of thymus lobule only and their appearance seems to be compatible with TEC morphology (90).

The neuropeptide NT is known to be involved in the modulation of dopamine signalling in the brain (110). NT has been found to be expressed in human TEC (111) and it has been reported to modulate cell functions of both innate and adaptive immunity $(112,113)$. The prevalent localization of NT on the medullary zone, where the thymus dopaminergic system has been specifically localized $(12,66)$, may support this hypothesis, indicating that NT has a functional role in the thymus medullary environment (90). These findings lead us to hypothesize the potential involvement of NT in thymus dopaminergic signalling.

\section{Conclusions}

In the last three decades, strong evidence has been gathered for a functional link between the nervous and immune systems, opening a new area of investigation: the neuroimmune modulation $(10,11,58)$.

The rich nerve fiber network in the thymus parenchyma forms a complex scenario where T-lymphocyte maturation is under strict control. The large amount of data collected thus far indicates that there is step by step neuronal control of lymphocyte maturation in and release from the thymus. In addition, neurotransmitters involved in signal transmission are widely modulated by neuropeptide co-secretion, adding further complexity to the nervous system control on the thymus microenvironment and lymphocyte maturation. Furthermore, immune cells synthesize, store and release neurotransmitters and neuropeptides, performing a secretory/ paracrine activity that contributes to regulate the maturation and function of immune cells. It is not of secondary importance that thymus parenchymal cells are able to secrete endocrine factor and are responsive to different circulating endocrine factors.

Alteration of these complex relationships has been associated with several diseases affecting the physiological function of the immune system, such as myastenia gravis, multiple sclerosis and functional alteration in aging $(45,90,114)$.

The implications of these findings for immune system function merit particular attention, especially in the field of neurological disease, in which neurotransmitter signalling shows altered responses. Similarly, further study is needed to examine the therapeutic uses of drugs that affect neurotransmitters, especially with regard to their side-effects on immune function.

Investigations into neuroimmune modulation may lead to improved understanding of the physiological and pathological mechanisms involved in the immune system. 


\section{References}

1. Benoit $\mathrm{C}$ and Mathis D: T-lymphocyte differentiation and biology. In: Fundamental Immunology. Paul W (ed) 4th edition. Lippincott-Raven, Philadelphia, PA, pp367-409, 1999.

2. Haks MC, Oostervegel MA, Blom B, Spits HM and Kruisbeek A Cell-fate decision in early T-cell development: regulation by cytokine receptors and the pre-TCR. Semin Immunol 11: 23-37, 1999.

3. Werlen G, Hausmann B, Naeher D and Palmer E: Signaling life and death in the thymus: timing is everything. Science 299 $1859-1863,2003$

4. Kendall MD and Al-Shawaf AA: Innervation of rat thymus gland. Brain Behav Immun 5: 9-28, 1991.

5. Boyd RL, Tucek CL, Godfrey DI, Izon DJ, Wilson TJ, Davidson NJ, Bean AG, Ladyman HM, Ritter MA and Hugo P: The thymic microenvironment. Immunol Today 14: 445-59, 1993.

6. Res P and Spits H: Developmental stages in the human thymus. Semin Immunol 11: 39-46, 1999.

7. Anderson G, Harman BC, Hare KJ and Jenkinson EJ: Microenvironmental regulation of T-cell development in the thymus. Semin Immunol 12: 457-464, 2000.

8. Anderson G and Jenkinson EJ: Lymphostromal interactions in thymic development and function. Nature Rev Immunol 1: 31-40, 2001.

9. Savino W and Dardenne M: Neuroendocrine control of thymus physiology. Endocr Rev 21: 412-443, 2000.

10. Rezzani R, Bonomini F and Rodella LF: Histochemical and molecular overview of the thymus as site for T-cells development. Prog Histochem Cytochem 43: 73-120, 2008.

11. Mignini F, Streccioni V and Amenta F: Autonomic innervation of immune organs and neuroimmune modulation. Auton Autacoid Pharmacol 23: 1-25, 2003.

12. Mignini F, Sabbatini M, D'Andrea V and Cavallotti C: Intrinsic innervation and dopaminergic markers after experimental denervation in rat thymus. Eur J Histochem 54: e17, 2010 .

13. Bockman DE: Development of the thymus. Microsc Res Tech 38 209-215, 1997.

14. Sultana DA, Tomita S, Hamada M, Iwanaga Y, Kitahama Y, Khang NV, Hirai S, Ohigashi I, Nitta S, Amagai T, Takahashi S and Takahama Y: Gene expression profile of the third pharyngeal pouch reveals role of mesenchymal MafB in embryonic thymus development. Blood 113: 2976-2987, 2009.

15. Gordon J, Wilson VA, Blair NF, Sheridan J, Farley A, Wilson L, Manley NR and Blackburn CC: Functional evidence for a single endodermal origin for the thymic epithelium. Nat Immunol 5: 546-53, 2004.

16. Gordon J and Manley NR: Mechanisms of thymus organogenesis and morphogenesis. Development 138: 3865-3878, 2011.

17. Taub DD and Longo DL: Insight into thymic aging and regeneration. Immunol Rev 205: 72-93, 2005.

18. Sutherland JS, Goldberg GL, Hammett MV, Uldrich AP, Berzins SP, Heng TS, Blazar BR, Millar JL, Malin MA, Chidgey AP and Boyd RL: Activation of thymic regeneration in mice and humans following androgen blockade. J Immunol 175 2741-2753, 2005

19. Cavallotti C, D'Andrea V, Tonnarini G, Cavallotti C and Bruzzone P: Age-related changes in the human thymus studied with scanning electron microscopy. Micros Res Tech 71: 573-578, 2008.

20. Petrie HT: Role of thymic organ structure and stromal composition in steady-state postnatal T-cell production. Immunol Rev 189: 8-19, 2002

21. Germain RN: T-cell development and the CD4-CD8 lineage decision. Nat Rev Immunol 2: 309-322, 2002.

22. Anderson M, Anderson SK and Farr AG: Thymic vasculature: organizer of the medullary epithelial compartment? Int Immunol 12: 1105-1110, 2000

23. Pearse G: Normal structure, function and histology of the thymus. Toxicol Pathol 34: 504-514, 2006.

24. Petrie HT and Zúñiga-Pflücker JC: Zoned out: functional mapping of stromal signaling microenvironments in the thymus. Ann Rev Immunol 25: 649-679, 2007

25. Gray DH, Ueno T, Chidgey AP, Malin M, Goldberg GL, Takahama Y and Boyd RL: Controlling the thymic microenvironment. Curr Op Immunol 17: 137-143, 2005.

26. Bodey B: Thymic reticulo-epithelial cells: key cells of neuroendocrine regulation. Expert Opin Biol Ther 7: 939-949, 2007.
27. Patel DD and Haynes BF: Cell adhesion molecules involved in intrathymic T-cell development. Semin Immunol 5: 282-292, 1993.

28. Van de Wijngaert FP, Kendall MD, Schuurman HJ, Rademakers LH and Kater L: Heterogeneity of epithelial cells in the human thymus. An ultrastructural study. Cell Tissue Res 237: 227-237, 1984.

29. Le PT and Singer KH: Human thymic epithelial cells: adhesion molecules and cytokine production. Int J Clin Lab Res 23: 56-60, 1993.

30. Prockop SE and Petrie HT: Regulation of thymus size by competition for stromal niches among early T-cell progenitors. J Immunol 173: 1604-1611, 2004

31. Savino W, Mendes-da-Cruz DA, Smaniotto S, Silva-Monteiro E and Villa-Verde DM: Molecular mechanisms governing thymocyte migration: combined role of chemokines and extracellular matrix. J Leukoc Biol 75:951-961, 2004.

32. Savino W, Dalmau SR and Dealmeida VC: Role of extracellular matrix-mediated interactions in thymocyte migration. Dev Immunol 7: 279-291, 2000.

33. Villa-Verde DM, Silva-Monteiro E, Jasiulionis M, Farias-de-Oliveira DA, Brentani RR, Savino W and Chammas R: Galectin-3 modulates carbohydrate-dependent thymocyte interactions with the thymic microenvironment. Eur J Immunol 32 : 1434-1444, 2002.

34. Aoudjit F, Masure S, Opdenakker G, Potworoski EF and St-Pierre Y: Gelatinase B (MMP-9), but not its inhibitor (TIMP-1), dictates the growth rate of experimental thymic lymphoma. Int J Cancer 82: 743-747, 1999.

35. Wilkinson B, Owen JJ and Jenkinson EJ: Factors regulating stem cell recruitment to the fetal thymus. J Immunol 162: 3873-3881, 1999.

36. Lannes-Vieira J, Dardenne M and Savino W: Extracellular matrix components of the mouse thymus micrenvironment: ontogenetic studies and modulation by glucocorticoid hormones. J Histochem Cytochem 39: 1539-1546, 1991.

37. Siemion I, Kluczyk A and Cebrat M: The peptide molecular links between the central nervous and the immune systems. Amino Acids 29: 161-176, 2005.

38. Lunin SM and Novoselova EG: Thymus hormones as prospective anti-inflammatory agents. Exper Opin Ther Targets 14: 775-786, 2010.

39. Leposavić G, Pilipović I and Perišić M: Cellular and nerve fibre catecholaminergic thymic network: steroid hormone dependent activity. Physiol Res 60 (Suppl. 1): S71-S82, 2011

40. Artico M, Cavallotti C, Cameroni $M$ and Cavallotti D Interleukin $1 \beta$ as simulator of the rat thymus. Cytokine 15: 261-265, 2001.

41. Berczi I, Quintanar-Stephano A and Kovacs K: Neuroimmune regulation in immunecompetence, acute illness and healing. Ann NY Acad Sci 1153: 220-239, 2009.

42. Tollefson L and Bulloch K: Dual-label retrograde transport: CNS innervation of the mouse thymus distinct from other mediastinum viscera. J Neurosci Res 25: 20-28, 1990.

43. Mićić M, Leposavić G, Ugresić N, Bogojević M and Isaković K: Parasympathetic innervation of the rat thymus during first life period: histochemical and biochemical study. Thymus 19: 173-182, 1992

44. Cavallotti D, Artico M,Iannetti G and Cavallotti C: Quantification of acetylcholinesterase-positive structures in human thymus during development and aging. Neurochem Int 36: 75-82, 2000.

45. Artico M, Cavallotti C, Tranquilli Leali FM, Falconi M and Cavallotti D: Effect of interferon on human thymus microenvironment. Immunol Lett 85: 19-27, 2003

46. Zimring JC, Kapp LM, Yamada M, Wess J and Kapp JA Regulation of $\mathrm{CD} 8^{+}$cytolytic $\mathrm{T}$ lymphocyte differentiation by a cholinergic pathway. J Neuroimmunol 164: 66-75, 2005.

47. Nance DM and Sanders VM: Autonomic innervation and regulation of the immune system (1987-2007). Brain Behav Immun 21: 736-745, 2007.

48. Trotter RN, Stornetta RL, Guyenet PG and Roberts MR Transneuronal mapping of the CNS network controlling sympathetic outflow to the rat thymus. Auton Neurosci 131: 9-20, 2007.

49. Besedovsky HO and del Rey A: Immune-neuro-endocrine interactions: facts and hypotheses. Endocr Rev 17: 64-102, 1996.

50. Al-Shawaf AA, Kendal MD and Cowen T: Identification of neural profiles containing vasoactive intestinal polypeptide, acetylcholinesterase and catecholamines in the rat thymus. J Anat 174: 131-143, 1991. 
51. Vizi ES and Elenkov IJ: Nonsynaptic noradrenaline release in neuro-immune responses. Acta Biol Hung 53: 229-244, 2002

52. Cavallotti C, Artico N and Cavallotti D: Occurrence of adrenergic nerve fibers and noradrenaline in thymus gland of juvenile and aged rats. Immunol Lett 70: 53-62, 1999.

53. Müller $S$ and Weihe E: Interrelation of peptidergic innervation with mast cells and ED1-positive cells in rat thymus. Brain Behav Immun 5: 55-72, 1991

54. Artico M, Cavallotti C and Cavallotti D: Adrenergic nerve and mast cells: correlation in rat thymus. Immunol Lett 84: 69-76, 2002.

55. Leposavić G, Mićić M, Ugresić N, Bogojević M and Isaković K: Components of sympathetic innervation of the rat thymus during late fetal and postnatal development: histofluorescence and biochemical study. Sympathetic innervation of the rat thymus. Thymus 19: 77-87, 1992.

56. Vizi ES, Orsó E, Osipenko ON, Hasko G and Elenkov IJ: Neurochemical, electrophysiological and immunocytochemical evidence for a noradrenergic link between the sympathetic nervous system and thymocytes. Neuroscience 68: 1263-1276, 1995.

57. Leposavić G, Pilipović I, Radojević K, Pešić V, Perišić M and Kosec D: Cathecolamines as immunomodulators: a role for adrenoceptor-mediated mechanisms in fine tuning of T-cell development. Autonom Neurosci 144: 1-12, 2008.

58. Elenkov IJ, Wilder RL, Chrousos GP and Vizi ES: The sympathetic nerve-an integrative interface between two supersystems: the brain and the immune system. Pharmacol Rev 52: 595-638, 2000.

59. Madden KS and Felten DL: $\beta$-adrenoceptor blockade alters thymocyte differentiation in aged mice. Cell Mol Biol 47: 189-196, 2001

60. Kavelaars A: Regulated expression of $\alpha-1$ adrenergic receptors in the immune system. Brain Behav Immun 16: 799-807, 2002.

61. Pešić V, Kosec D, Radojević K, Pilipović I, Perišić M, Vidić-Danković B and Leposavić G: Expression of $\alpha 1$-adrenoceptors on thymic cells and their role in fine tuning of thymopoiesis. J Neuroimmunol 214: 55-66, 2009.

62. Cavallotti D, Artico M, Iannetti G and Cavallotti C: Occurrence of adrenergic nerve fibers in human thymus during immune response. Neurochem Int 40: 211-221, 2002.

63. Wrona D: Neural-immune interactions: an integrative view of the bidirectional relationship between the brain and the immune systems. J Neuroimmunol 172: 38-58, 2006.

64. Leposavić G, Radojević K, Vidić-Danković B,Kosec D,Pilipović I and Perišić M: Early postnatal castration affects thymic and thymocyte noradrenaline levels and $\beta$-adrenoceptor-mediated influence on the thymopoiesis in adult rats. J Neuroimmunol 182 100-115, 2007.

65. Nakano K, Higashi T, Takagi R, Hashimoto K, Tanaka Y and Matsushita S: Dopamine released by dendritic cells polarizes Th2 differentiation. Int Immunol 21: 645-654, 2009.

66. Mignini F, Tomassoni D, Traini E and Amenta F: Dopamine, vesicular transporters and dopamine receptor expression and localization in rat thymus and spleen. J Neuroimmunol 206: 5-13, 2009.

67. Nijima A, Hori T, Katafuchi T and Ichijo T: The effect of interleukin- $1 \beta$ on the efferent activity of the vagus nerve to the thymus. J Auton Nerv Syst 54: 137-144, 1995

68. Dovas A, Lucchi ML, Bortoloami R, Grandis A, Palladino AR, Banelli E, Caretta M, Magni F and Paolocci N: Collaterals of recurrent laringeal nerve fibres innervate the thymus: a fluorescent tracer and HRP investigation of efferent vagal neurons in the rat brainstem. Brain Res 809: 141-148, 1998.

69. Mitchell B, Kendall M, Adam E and Schumacher U: Innervation of the thymus in normal and bone marrow reconstituted severe combined immunodeficient (SCID) mice. J Neuroimmunol 75 19-27, 1997.

70. Antonica A, Ayroldi E, Magni F and Paolocci N: Lymphocyte traffic changes induced by monolateral vagal denervation in mouse thymus and peripheral lymphoid organs. J Neuroimmunol 64 : $115-122,1996$.

71. Rinner I, Kawashima K and Schauenstein K: Rat lymphocytes produce and secrete acetylcholine in dependence of differentiation and activation. J Neuroimmunol 81: 31-37, 1998.

72. Rinner I, Globerson A, Kawashima K, Korsatko W and Schauenstein K: A possible role for acetylcholine in the dialogue between thymocytes and thymic stroma. Neuroimmunomodulation 6: 51-55, 1999 .
73. Yamada T, Murayama T and Nomura Y: Muscarinic acetylcholine receptors on rat thymocytes: their possible involvement in DNA fragmentation. Jpn J Pharmacol 73: 311-316, 1997.

74. Kendall MD: Functional anatomy of the thymic microenvironment. J Anat 177: 1-29, 1991.

75. Kohm AP and Sanders VM: Norepinephrine and $\beta 2$-adrenergic receptor stimulation regulate $\mathrm{CD} 4^{+} \mathrm{T}$ and $\mathrm{B}$ lymphocytes function in vitro and in vivo. Pharmacol Rev 53: 487-525, 2001.

76. Sarkar C, Basu B, Chakroborty D, Dasgupta PS and Basu S: The immunoregulatory role of dopamine: an update. Brain Behav Immun 24: 525-528, 2010.

77. Mignini F, Sabbatini M, Capacchietti M, Amantini C, Bianchi E, Artico $\mathrm{M}$ and Tammaro A: T-cell subpopulations express a different pattern of dopaminergic markers in intra- and extrathymic compartments. J Biol Regul Homeost Agents 27: 463-475, 2013.

78. Mignini F, Traini E, Tomassoni D and Amenta F: Dopamine plasma membrane transporter (DAT) in rat thymus and spleen: an an immunochemical and immunohistochemical study. Autonom Autocoid Pharmacol 26: 183-189, 2006

79. Cosentino M, Fietta AM, Ferrari M, Rasini E, Bombelli R, Carcano E, Saporiti F, Meloni F, Marino F and Lecchini S: Human $\mathrm{CD}^{+} \mathrm{CD} 25^{+}$regulatory $\mathrm{T}$-cells selectively express tyrosine hydroxylase and contain endogeneous catecholamines subserving an autocrine/paracrine inhibitory functional loop. Blood 109: 632-642, 2007.

80. Oberbek R: Catecholamines: physiological immunomodulators during health and illness. Curr Med Chem 13: 1979-1989, 2006.

81. Caronti B, Calderaro C, Passarelli F, Palladini G and Pontieri FE: Dopamine receptor mRNAs in the rat lymphocytes. Life Sci 62: $1919-1925,1998$

82. Kavelaars A, Cobelens PM, Teunis MA and Heijnen CJ: Changes in innate and acquired immuno response in mice with targeted deletion of the dopamine transporter gene. J Neuroimmunol 161: 162-168, 2005.

83. Olanow CW: The pathogenesis of cell death in Parkinson's disease-2007. Mov Disord 17 (Suppl): S335-S342, 2007.

84. Cook-Mills JM, Cohen RL, Perlman RL and Chambers DA: Inhibition of lymphocyte activation by catecholamines: evidence for a non-classical mechanism of catecholamine action. Immunology 85: 544-549, 1995.

85. Tsao CW, Lin YS and Cheng JT: Effect of dopamine on immune cell proliferation in mice. Life Sci 61: PL361-PL371, 1997.

86. Ilani T, Strous RD and Fuchs S: Dopaminergic regulation of immune cells via D3 dopamine receptor: a pathway mediated by activated T-cells. FASEB J 18: 1600-1602, 2004

87. Sarkar C, Das S, Chakroborty D, Chowdhury UR, Basu B, Dasgupta PS and Basu S: Cutting Edge: stimulation of dopamine D4 receptors induce T-cell quiescence by upregulating Kruppel-like factor-2 expression through inhibition of ERK1/ERK2 phosphorylation. J Immunol 177: 7525-7529, 2006.

88. Trejter M, Warchol JB, De Caro R, Brelinska R, Nussdorfer GG and Malendowcz LK: Studies on the involvement of endogenous neuropeptides in the control of thymocyte proliferation in the rat. Histol Histopathol 16: 155-158, 2001.

89. Silva AB and Palmer DB: Evidence of conserved neuroendocrine interactions in the thymus: intrathymic expression of neuropeptides in mammalian and non-mammalian vertebrates. Neuroimmunomodulation 18: 264-270, 2011.

90. Mignini F, Sabbatini M, D'Andrea V and Cavallotti C: Neuropeptides of human thymus in normal and pathological conditions. Peptides 32: 920-928, 2011.

91. Bellinger DL, Lorton D, Romano TD, Olschowka JA, Felten SY and Felten DL: Neuropeptide innervation of lymphoid organs. Ann NY Acad Sci 594:17-33, 1990.

92. Krantz A, Kendall MD and von Gaudecker B: Studies on rat and human thymus to demonstrate immunoreactivity of calcitonin gene-related peptide, tyrosine hydroxylase and neuropeptide $\mathrm{Y}$. J Anat 191: 441-450, 1997.

93. Weihe E, Nohr D, Michel S, Müller S, Zentel HJ, Fink T and Krekel J: Molecular anatomy of the neuro-immune connection. Int J Neurosci 59: 1-23, 1991.

94. De la Fuente M, Del Rio M, Victor VM and Medina S: Neuropeptide Y effects on murine natural killer activity: changes with ageing and cAMP involvement. Regul Pept 101: 73-79, 2001

95. Bedoui S, Kawamura N, Straub RH, Pabst R, Yamamura T and von Hörsten S: Relevance of neuropeptide $Y$ for the neuroimmune crosstalk. J Neuroimmunol 134: 1-11, 2003. 
96. Delgado M, Martinez C, Leceta J and Gomariz RP: Vasoactive intestinal peptide in thymus: synthesis, receptors and biological actions. Neuroimmunomodulation 6: 97-107, 1999.

97. Bellinger DL, Lorton D, Horn L, Brouxhon S, Felten SY and Felten DL: Vasoactive intestinal polypeptide (VIP) innervation of rat spleen, thymus and lymph nodes. Peptides 18: 1139-1149, 1997.

98. Delgado M, Garrido E, Martinez C, Leceta J and Gomariz RP: Vasoactive intestinal peptide and pituitary adenylate cyclaseactivating polypeptides (PACAP27 and PACAP38) protect $\mathrm{CD} 4^{+} \mathrm{CD} 8^{+}$thymocytes from glucocorticoid-induced apoptosis. Blood 87: 5152-5161, 1996.

99. Ganea D, Gonzales-Rey E and Delgado M: A novel mechanism for immunosuppression: from neuropeptides to regulatory T cells. J Neuroimmune Pharmacol 1: 400-409, 2006.

100. Lorton D, Bellinger DL, Felten SY and Felten DL: Substance P innervation of the rat thymus. Peptides 11: 1269-1275, 1990.

101.Jurjus AR, More N and Walsh RJ: Distribution of substance $\mathrm{P}$ positive cells and nerve fibers in the rat thymus. J Neuroimmunol 90: 143-148, 1998.

102. Piantelli M, Maggiano N, Larocca LM, Ricci R, Ranelletti FO, Lauriola $\mathrm{L}$ and Capelli A: Neuropeptide-immunoreactive cells in human thymus. Brain Behav Immun 4: 189-197, 1990.

103. Bulloch K, Radojcic T, Yu R, Hausman J, Lenhard L and Baird S: The distribution and function of calcitonin gene-related peptide in the mouse thymus and spleen. Psycho Neuro Endocrin Immunol 4: 186-194, 1991.

104. Bulloch K, McEwen BS, Diwa A, Radojcic T, Hausman J and Baird S: The role of calcitonin gene-related peptide in the mouse thymus revisited. Ann NY Acad Sci 25: 129-136, 1994.

105.Xing L, Guo J and Wang X: Induction and expression of $\beta$-calcitonin gene-related peptide in rat T lymphocytes and its significance. J Immunol 165: 4359-4366, 2000.

106. Bulloch K, McEwen BS and Diwa A and Baird S: Relationship between dehydroepiandrosterone and calcitonin gene-related peptide in the mouse thymus. Am J Physiol 268: E168-E173, 1995.
107.Bulloch K, McEwen BS, Nordberg J, Diwa A and Baird S: Selective regulation of T-cell development and function by calcitonin gene-related peptide in thymus and spleen. An example of differential regional regulation of immunity by the neuroendocrine system. Ann NY Acad Sci 840: 551-562, 1998.

108. Sakuta H, Inaba K and Muramatsu S: Calcitonin gene-related peptide enhances apoptosis of thymocytes. J Neuroimmunol 67: 103-109, 1996.

109. Polak JM and Bloom SR: The central and peripheral distribution of neurotensin. Ann NY Acad Sci 400: 75-93, 1982.

110. Katsanos GS, Anogianaki A, Castellani ML, Ciampoli C, De Amicis D, Orso C, Pollice R, Vecchiet J, Tetè S, Salini V, Caraffa A, Patruno A, Shaik YB, Kempuraj D, Doyle R, Antinolfi PL, Cerulli G, Conti CM, Fulcheri M, Neri G and Sabatino G: Biology of neurotensin: revisited study. Int J Immunopathol Pharmacol 21: 255-259, 2008.

111. Vanneste Y, Thome AN, Vandersmissen E, Charlet C, Franchimont D, Martens H, Lhiaubet AM, Schimpff RM, Rostène W and Geenen V: Identification of neurotensin-related peptides in human thymic epithelial cell membranes and relationship with major histocompatibility complex class I molecules. J Neuroimmunol 76: 161-166, 1997.

112. Lhiaubet AM, Avard C and Schimpff RM: Apparent functionality but impractical quantification of neurotensin receptors on human peripheral lymphocytes. Hormone Res 49: 233-239, 1998.

113. Ramez M, Bagot M, Nikolova M, Boumsell L, Vita N, Chalon P, Caput D, Ferrara P and Bensussan A: Functional characterization of neurotensin receptors in human cutaneous $\mathrm{T}$ cell lymphoma malignant lymphocytes. J Invest Dermatol 117: 687-693, 2001.

114. Hannestad J, Monjil DF, Díaz-Esnal B, Cobo J and Vega JA: Age-dependent changes in the nervous and endocrine control of the thymus. Micros Res Tech 63: 94-101, 2004. 